\title{
Resistencia antimicrobiana de Gallibacterium anatis aisladas de gallinas de postura comercial en Sonora, México
}

\section{Antimicrobial resistance of Gallibacterium anatis isolates from breeding and laying commercial hens in Sonora, Mexico}

\author{
Reyna Fabiola Osuna Chávez ${ }^{a}$, Ramón Miguel Molina Barrios ${ }^{a^{*}}$, Javier Arturo Munguía Xóchihuaa , Juan \\ Francisco Hernández Chávez ${ }^{a}$, José Benito López León ${ }^{b}$, Martín Acuña Yanes ${ }^{b}$, Víctor Arturo Fernández \\ Martínez ${ }^{b}$, Jorge Robles Mascareñoa , Jesús Gabriel Adrián Icedo Escalante ${ }^{a}$
}

\begin{abstract}
RESUMEN
Se consiguieron identificar 23 aislamientos de Gallibacterium anatis, a través de pruebas convencionales de cultivo y bioquímicas, confirmándose su identificación a través del método de PCR. Se les efectuó la prueba de difusión en placa para determinar la resistencia antimicrobiana a los antibióticos más utilizados en el área avícola. Los aislamientos fueron más susceptibles a ceftiofur $(73 \%)$ y florfenicol $(68 \%)$; todos los aislamientos mostraron resistencia marcada a penicilina, tilosina, lincomicina, ampicilina, enrofloxacina, oxitetraciclina, norfloxacina y cefalexina. La presencia de Gallibacterium anatis se asocia a problemas respiratorios y reproductivos en las poblaciones de gallinas de postura comercial. Los aislamientos mostraron una resistencia marcada a distintos antibióticos, probablemente por la medicación desmedida ante la presencia de este microorganismo.
\end{abstract}

PALABRAS CLAVE: Gallibacterium anatis, PCR, Resistencia, Susceptibilidad, Antimicrobianos.

\begin{abstract}
It was able to identify 23 isolates of Gallibacterium anatis through conventional culture and biochemical tests, and identification confirmed through PCR method. A disk diffusion test determined antimicrobial resistance to commonly used antibiotics in the poultry area. Isolates were more susceptible to ceftiofur (73 \%) and florfenicol (68 \%). All isolates showed marked resistance to penicillin, tylosin, lincomycin, ampicillin, enrofloxacin, oxytetracycline, norfloxacin and cephalexin. The presence of Gallibacterium anatis is associated with respiratory and reproductive problems in populations of commercial laying hens. Isolates showed marked resistance to different antibiotics, probably due to excessive medication in the presence of this organism.
\end{abstract}

KEY WORDS: Gallibacterium anatis, PCR, Resistance, Susceptibility, Antimicrobials.

Recibido el 19 de noviembre de 2013. Aceptado el 16 de febrero de 2015

${ }^{a}$ Departamento de Ciencias Agronómicas y Veterinarias. Instituto Tecnológico de Sonora. Antonio Caso S/N 85093. Cd. Obregón, Sonora. México.

${ }^{b}$ Pecuarius Laboratorios S.A. de C.V. Cd. Obregón, Sonora. México.

*Autor de correspondencia: rammol62@yahoo.com. 
Una de las causas de grandes pérdidas económicas en la industria avícola son las enfermedades reproductivas y respiratorias de las aves, las cuales causan aumento en los costos por el

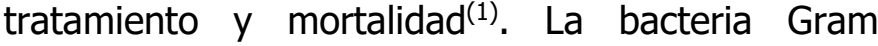
negativa de Gallibacterium anatis causa salpingitis y peritonitis en gallinas ponedoras, lo cual disminuye la producción de huevo(2), ocasionando problemas en la avicultura moderna por presentar lesiones como atrofia folicular, ooforitis, septicemia, folículos deformes, peritonitis, agrandamiento de los riñones, enteritis, congestión, así como edema del tracto respiratorio ${ }^{(3,4,5)}$. Mirle et $a^{(1)}$ establecieron que Gallibacterium también ocasiona alteración en el tamaño del huevo, variación en la formación del cascarón y bajas significativas en la producción del 2 al $4 \%$, ocasionando grandes pérdidas económicas y aumento en los costos de producción por tratamientos, por lo que representa un gran reto sanitario y económico para la industria avícola mexicana. La compleja patogenia de $G$. anatis ha sido objeto de revisiones ${ }^{(6)}$. Es poco lo que se sabe hoy en día de la patogénesis y son pocos los factores de virulencia que se han identificado, como la toxina $\mathrm{RTX}^{(7)}$, las metaloproteasas con capacidad de degradar la IgG aviar ${ }^{(8)}$, y la fimbria F17-like ${ }^{(9)}$. Así mismo, se ha demostrado una incidencia del 48 al $61 \%$ y una alta prevalencia con el 95 de significancia, la cual es afectada por los niveles de bioseguridad $^{(3,10)}$.

Anteriormente $G$. anatis era considerado un agente secundario(1), debido a que este patógeno se encuentra en la flora normal de pollos sanos, por lo que causa intriga en cuanto a su patogenicidad primaria, que probablemente se encuentre influenciada por factores adicionales que causan la inmunosupresión de las aves, permitiendo que el agente oportunista de $G$. anatis actúe negativamente sobre el huésped ${ }^{(3,11,12)}$, sugiriendo que es una bacteria oportunista que puede convertirse en el agente primario para el desarrollo de la enfermedad ${ }^{(1,3,5)}$.

Aunado a esto, es importante conocer los factores de patogenia y virulencia para mejorar, entender y prevenir los efectos negativos de $G$. anatis(2); como también, la aparición de nuevas enfermedades, la modificación de la virulencia y la medicación desmedida, las cuales han contribuido a la resistencia y susceptibilidad antimicrobiana a los antibióticos, complicando la enfermedad; observando aumento de resistencia antimicrobiana entre varios miembros de la familia Pasteurellaceaes ${ }^{(13,14)}$.

El diagnóstico oportuno de esta enfermedad, podría prevenir algunos inconvenientes. Para ello, se debe integrar el trabajo de campo considerando la observación de signos clínicos, los resultados obtenidos a partir de las muestras enviadas al laboratorio, la identificación del agente y el diagnóstico diferencial con otras enfermedades. De igual manera un tratamiento eficaz con antibióticos específicos permitiría mantener altos niveles de salud animal. Sin embargo, en México, los productores de aves, suelen fracasar en el tratamiento con antibióticos utilizados contra la infección de $G$. anatis ${ }^{(15)}$, debido a que los organismos pertenecientes a la familia de las Pasteurellaceae muestran resistencia recurrente debido al uso desmedido de antibióticos no específicos $^{(13)}$. Es por esto, que el objetivo del presente trabajo fue determinar la susceptibilidad y resistencia a diferentes antibióticos, incluyendo los más utilizados para el tratamiento de $G$. anatis.

Al iniciar la investigación, fue necesario aislar la bacteria a partir de muestras de tejidos. Los aislamientos, se obtuvieron de 189 granjas avícolas establecidas en el estado de Sonora, las cuales están integradas por múltiples casetas, durante el periodo 2007-2011(16). Se seleccionaron 30 granjas de postura comercial de forma dirigida por presentar sintomatología de tipo respiratorio y reproductivo como referencia, donde se obtuvieron muestras de 20 aves. El procedimiento de necropsia se realizó de acuerdo a lo establecido en el manual de necropsias y toma de muestras de las aves ${ }^{(17,18)}$. Se buscaron lesiones de tipo reproductivo y respiratorio, tomándose muestras de diversos tejidos como los cornetes, tráquea, pulmones, hendidura palatina, hígado, bazo, riñones, folículos y peritoneo. La superficie del tejido muestreado se cauterizó con una espátula caliente antes de introducir el hisopo estéril con el objeto de prevenir cualquier tipo de contaminación, inoculándose posteriormente en cajas Petri de plástico estériles desechables, con agar sangre (BD Bioxon), con sangre estéril desfibrinada de bovino al 5\% y agar Mac Conkey (BD 
Bioxon), incubándose a $37^{\circ} \mathrm{C}$ de 18 a $24 \mathrm{~h}$ en una incubadora microbiológica (1535 Shel Lab). Posteriormente, se realizó la identificación bacteriana de los aislamientos mediante pruebas convencionales de cultivo de agar sangre de bovino al $5 \%$, identificando características morfológicas y de hemólisis ${ }^{(19)}$. Las bacterias se purificaron y se seleccionaron morfológicamente en base a lo descrito por Christensen et a ${ }^{(19)}$, quienes mencionan que las colonias deben tener un diámetro de 1 a 2 $\mathrm{mm}$, ser circulares, convexas y grisáceas traslúcidas. Las bacterias se colorearon con tinción de Gram, identificándose como cocobacilos Gram negativos, de acuerdo a lo establecido por Rimler et $a^{(20)}$, en un microscopio Olympus CX41.

Así mismo, la identificación bioquímica se realizó de cultivos de menos de $24 \mathrm{~h}$ de vida, por medio del sistema comercial para cocobacilos Gram negativos (NC33) de MicroScan Renok ${ }^{\top \mathrm{M}}$, según especificaciones del fabricante en el procedimiento en un equipo AS-4 con el software LABPRO MICROSCAN; las placas inoculadas (NC33) se incubaron a $37^{\circ} \mathrm{C}$ durante $24 \mathrm{~h}$ en una incubadora 1535 Shel Lab. La interpretación fue visual; cada pozo se evaluó por su cambio de color específico, indicando así la presencia de una reacción metabólica basándose en la tabla de MicroScan Renok $^{\text {TM }}$ Gram negativos ${ }^{(21)}$, debido a que la base de datos del MicroScan no poseía referencias para $G$. anatis. Para complementar las pruebas y poder biotipificar las bacterias, se realizaron bioquímicas de cuatro carbohidratos más (glucosa, maltosa, trehalosa y D-xilosa) (BD Bioxon). Todas las bioquímicas se corrieron dos veces para detectar cualquier error efectuado durante el procedimiento. Así mismo, se ejecutó la prueba para buscar la

Cuadro 1. Clasificación bioquímica de Gallibacterium anatis

\begin{tabular}{|c|c|c|c|c|c|c|c|}
\hline BIOVAR & Arabinosa & $\mathrm{D}(+)$ xylosa & Meso-inositol & $\mathrm{D}(-)$ sorbitol & Maltosa & Trehalosa & Dextrin \\
\hline Biovar 1 & - & $+/(+)$ & $+/(+)$ & + & + & $+/(+)$ & $+/(+)$ \\
\hline Biovar 2 & - & + & + & + & + & + & - \\
\hline Biovar 3 & - & + & $+/(+)$ & + & + & - & + \\
\hline Biovar 4 & - & + & $+/(+)$ & + & - & $+/(+)$ & $-/(+)$ \\
\hline Biovar 5 & - & + & - & - & + & + & $(+)$ \\
\hline Biovar 6 & - & + & - & + & + & + & + \\
\hline Biovar 7 & - & - & $(+)$ & + & + & + & + \\
\hline Biovar 8 & + & + & - & - & + & + & + \\
\hline Biovar 9 & - & + & $+/(+)$ & - & + & - & + \\
\hline Biovar 10 & - & + & - & + & + & + & - \\
\hline Biovar 11 & - & + & + & + & - & - & $-/(+)$ \\
\hline Biovar 12 & - & + & $+/(+)$ & - & - & $+/(+)$ & $-/(+)$ \\
\hline Biovar 13 & - & + & - & + & - & + & - \\
\hline Biovar 14 & - & - & + & + & + & - & - \\
\hline Biovar 15 & - & - & + & + & - & - & - \\
\hline Biovar 16 & - & - & - & + & - & + & - \\
\hline Biovar 17 & - & + & $+/(+)$ & - & - & - & - \\
\hline Biovar 18 & - & + & - & - & - & $+/(+)$ & $-/(+)$ \\
\hline Biovar 19 & - & + & - & - & - & - & - \\
\hline Biovar 20 & - & - & - & - & - & + & - \\
\hline Biovar 21 & - & - & - & - & - & - & - \\
\hline Biovar 22 & - & + & - & + & - & - & - \\
\hline Biovar 23 & - & - & - & - & + & + & + \\
\hline Biovar 24 & - & $+/(+)$ & $+/(+)$ & - & + & + & $+/(+)$ \\
\hline
\end{tabular}


presencia de la enzima oxidasa, con tiras reactivas

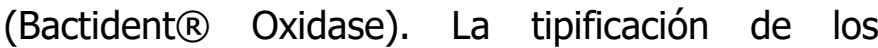
aislamientos se basaron en investigaciones anteriores, a partir de la fermentación de carbohidratos de (+) L-arabinosa, (+) D-xilosa, minositol, (-) D-sorbitol, maltosa, trehalosa y dextrina, diferenciando entre 24 biovares registrados ${ }^{(19,22)}$ (Cuadro 1).

Para complementar la identificación, se consideró identificar a $G$. anatis por la reacción en cadena de la polimerasa (PCR), y para esto fue necesario primero la extracción de ADN bacteriano genómico, proceso realizado mediante las instrucciones de QIAamp DNA Mini Kit (51306, QIAGEN), según especificaciones del proveedor. Para la cuantificación del ADN se utilizó un espectrofotómetro (Jenway, GENOVA) con celdas de cuarzo, a una absorbancia de 260 y $280 \mathrm{~nm}$. Para la confirmación molecular de los aislamientos bacterianos mediante la amplificación por PCR de los segmentos específicos de los genes de $G$. anatis. Las secuencias de oligonucleótidos se diseñaron en base a las 99 secuencias de 16S RNAr del Gen Bank ${ }^{(23)}$. Se seleccionó el oligonucleótido 1133fgal (5'TATTCTITGTTACCARCGG), el cual se prevé que es específico para Gallibacterium y no tiene la capacidad de amplificar el ADN de otros miembros de la familia Pasteurellaceae, dentro de las condiciones del PCR elegido donde se espera un amplicón de 790 pb. Para la amplificación inversa se eligió el oligonucleótidos del gen 235 rRNA con secuencia $114 r$ (5'-GGTTTCCCCATTCGG) reportados por Lane ${ }^{(24)}$ y Bojesen et $a^{(23)}$, esperando un amplicón de 1080 pb. Para esto se utilizó un termociclador (Mastercycler $\AA$ personal Eppendorf) en punto final. La reacción de PCR se llevó a la concentración final de $25 \mu \mathrm{l}$ con $2.5 \mu \mathrm{l} \mathrm{Mg} 10 \mathrm{X}$ Buffer, $0.85 \mu \mathrm{lgCl}_{2}(25 \mathrm{mM}), 0.5 \mu \mathrm{l}$ DNTP's mix $(2.5 \mathrm{mM})$, Primer F $0.25 \mu \mathrm{l}$ y Primer R $0.25 \mu \mathrm{l}$ (50 $\mu \mathrm{M}), 0.25 \mu \mathrm{l} \mathrm{Taq}(5 \mathrm{U} / \mu \mathrm{l}), 18.5 \mu \mathrm{l} \mathrm{H}_{2} \mathrm{O}$ libre de RNasas

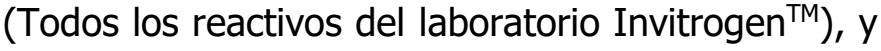
$2 \mu$ DNA de cada una de las muestras, obteniendo $25 \mu \mathrm{l}$ de volumen total. Las condiciones de la PCR fueron las siguientes: la desnaturalización de $95^{\circ} \mathrm{C}$ durante 4 min, seguido de 35 ciclos de $95^{\circ} \mathrm{C}$ por 30 seg cada uno, alineamientos de $54^{\circ} \mathrm{C}$ durante $1 \mathrm{~min}$ y 2 min a $72{ }^{\circ} \mathrm{C}$, seguido por la extensión final de 72
${ }^{\circ} \mathrm{C}$ durante $10 \mathrm{~min}$. El amplicón esperado se amplificó en gel agarosa al $1.6 \%$ teñido con bromuro de etidio(23), y posteriormente visualizados en un transiluminador UV (Macro Vue UV-25, Hoefer).

Para finalizar, el análisis de resistencia antimicrobiana se realizó mediante el método de Kirby-Bauer, descrito por el Laboratorio Internacional de Referencia: National Committe for Clinical Laboratory Standards $\left(\right.$ NCCLS) ${ }^{(25)}$. Se realizaron cultivos de los aislamientos de $G$. anatis en agar sangre de bovino al 5\%, utilizando sensidiscos de papel que contenían una distribución homogénea de antibiótico, para posteriormente incubar a $37^{\circ} \mathrm{C}$ por 18 a $24 \mathrm{~h}^{(26)}$.

Los antibióticos evaluados fueron los aminoglucósidos (gentamicina, estreptomicina, neomicina, kamicina, neo-kanamicina); betalactámicos (ampicilina, penicilina); fluoroquinolona (norfloxacina, enrofloxacina); cefalosporina (ceftiofur, cefalexina); fenicoles (florfenicol, tianfenicol); lincosamidas (lincoespectin, lincomicina); tetraciclinas (oxitetraciclina); macrólidos (tilosina); fosfonatos (fosfomicina) y sulfonamidas (sulfametoxazol). La concentración de los sensidiscos fue de $100 \mu \mathrm{g}$ en los nitrofuranos, 5 $\mu \mathrm{g}$ en las fluoroquinolonas y $30 \mu \mathrm{g}$ en todas las demás; todo esto es fundamentado en la Farmacopea Americana del Compendio de Normas o Estándares y Técnicas de Laboratorio. La interpretación de la susceptibilidad antimicrobiana se estableció en la medición del halo de inhibición, comparándolo con la concentración mínima inhibitoria (CIM) (27).

Se lograron aislar 23 cepas bacterianas de $G$. anatis, de las cuales la cepa de referencia y cuatro cepas más, fueron donadas de estudios anteriores. A pesar que se hicieron 600 muestreos, no se pudo aislar de todos los casos, posiblemente debido a que las aves se encuentran inmunizadas contra este microorganismo; sin embargo, el muestreo fue considerado exitoso, debido a que hubo un brote en el 2010-2011, lo que permitió que del $100 \%$ de las bacterias aisladas, el $34 \%$ correspondiera a $G$. anatis (Figura 1), ya que en otras circunstancias hubiera resultado complicado. El $70 \%$ de las bacterias se asilaron de pulmón, $30 \%$ en tráquea y $30 \%$ en folículos (Figura 2), lo que indica que este 
microorganismo causa patologías respiratorias y reproductivas. Las bacterias se identificaron morfológicamente en agar sangre de bovino al 5\%, apoyados en la técnica y morfología descrita por Christensen et $a{ }^{(19)}$.

En la identificación bioquímica se identificaron los aislamientos como G. anatis $19,22,28)$, realizando repetición de las pruebas con la finalidad de disminuir errores.

En la identificación molecular por PCR, se obtuvo una media de $20.5 \mu \mathrm{g} / \mathrm{ml}$ y una relación de

Figura 1. Porcentaje de bacterias aisladas en aves del sur de Sonora, durante en el período 2010 - 2011

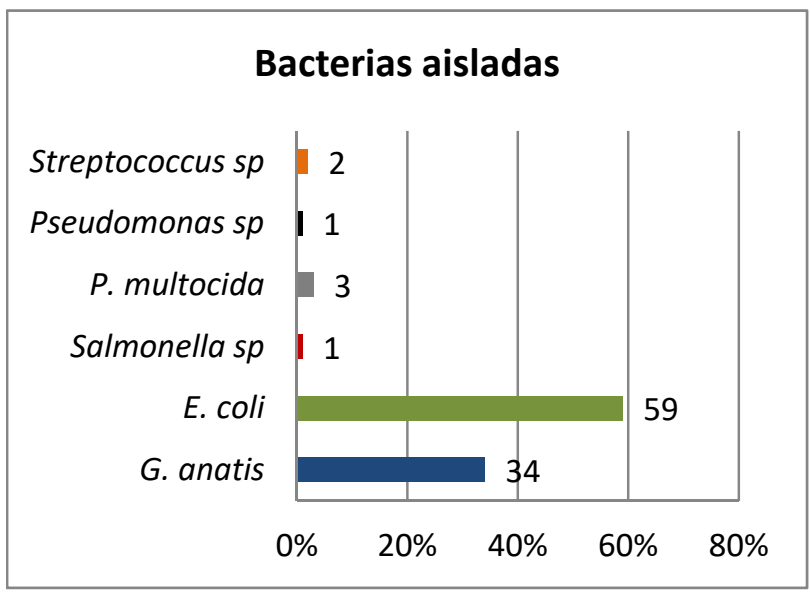

Figura 2. Porcentaje de órganos donde fueron aisladas las bacterias de Gallibacterium anatis

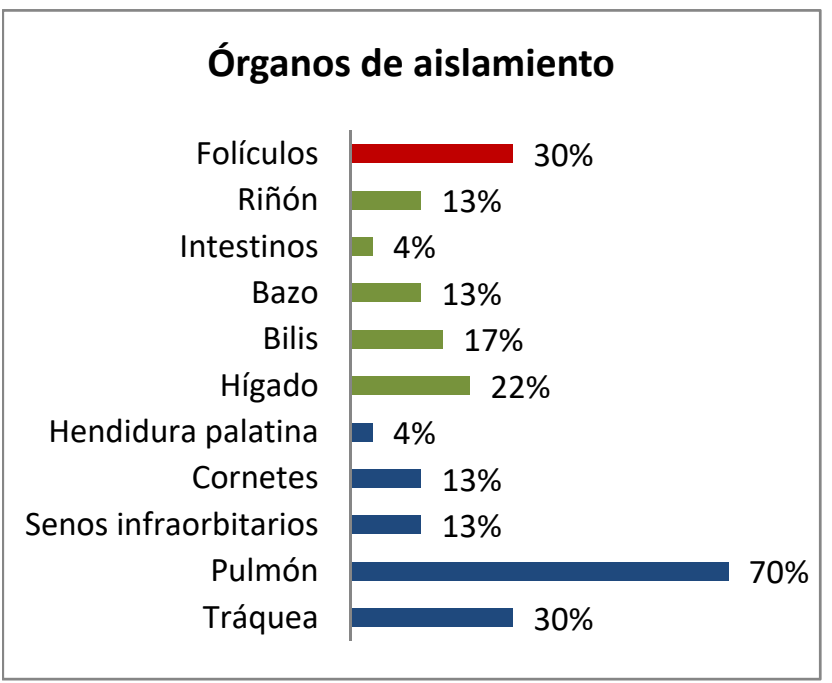

pureza de 1.8 en la extracción de ADN bacteriano; con esto fue posible continuar con el proceso, donde los productos de amplificación de las bacterias aisladas obtuvieron 790 pb y un segundo amplicón de $1080 \mathrm{pb}$, donde están ubicados los segmentos específicos de $G$. anatis que codifican para los genes $16 S$ rRNA y $23 S$ rRNA, según lo establecido por Bojesen et $a{ }^{(23)}$, confirmando como positivas a las 23 cepas aisladas (Figura 3).

En el análisis general de la resistencia antimicrobiana de los 23 aislamientos, los resultados revelaron que las bacterias presentaban mayor resistencia a la penicilina con el $100 \%$ y la ampicilina con el $95.7 \%$, ambos del grupo correspondientes a los betalactámicos. Lincomicina con el $95.7 \%$ y también tilosina con el 95.7 \% (Cuadro 2) (Figura 4). G. anatis reflejó más susceptibilidad a ceftiofur, con el $73.9 \%$, seguido de los fenicoles, donde se encuentra al florfenicol con el $65.2 \%$ y al tianfenicol con el $56.5 \%$. En los antibiogramas realizados a cada una de las bacterias aisladas, todos los aislamientos, a excepción de dos, mostraron una resistencia mayor al $50 \%$ de los antibióticos, demostrando, que la mayoría de los aislamientos de $G$. anatis en el estado de Sonora han creado resistencia marcada.

Los 23 aislamientos de $G$. anatis se obtuvieron de aves con patologías respiratorias y reproductivas; se identificaron macroscópicamente ${ }^{(19)}$, también se

Figura 3. Amplificación genética por PCR, de Gallibacterium anatis

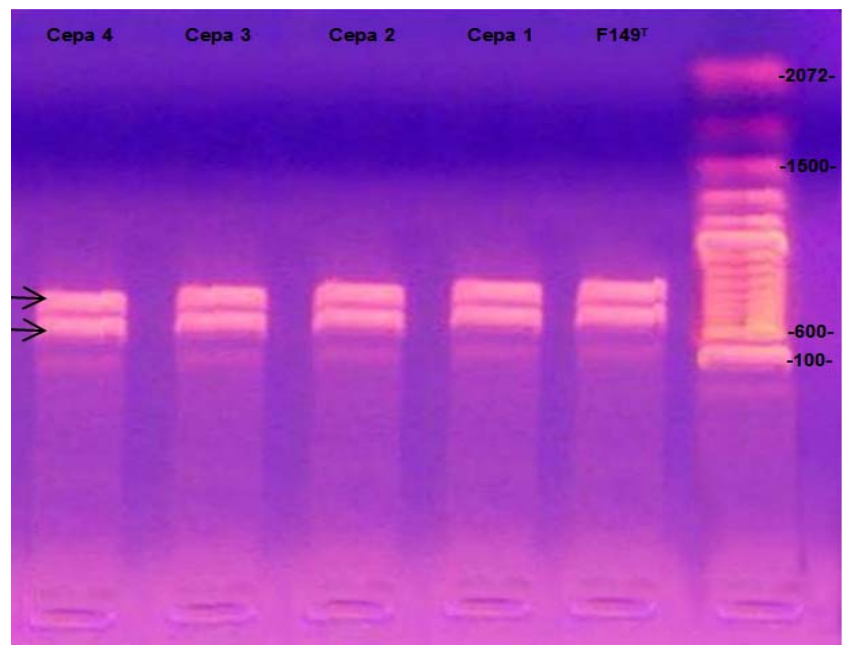


Cuadro 2. Susceptibilidad y resistencia de bacterias de Gallibacterium anatis aisladas en el Sur de Sonora, México

\begin{tabular}{|c|c|c|c|}
\hline & & $\begin{array}{l}\text { Susceptibilidad } \\
\text { No. (\%) }\end{array}$ & $\begin{array}{c}\text { Resistencia } \\
\text { No. }(\%)\end{array}$ \\
\hline \multicolumn{2}{|c|}{ AISLAMIENTOS } & 23 & 23 \\
\hline \multirow{5}{*}{ 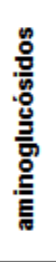 } & Gentamicina & $12(52.2)$ & $11(47.8)$ \\
\hline & Estreptomicina & $5(21.7)$ & $18(78.3)$ \\
\hline & Neomicina & $11(47.8)$ & $12(52.2)$ \\
\hline & Kanamicina & $13(56.5)$ & $10(43.5)$ \\
\hline & Neo-kanamicina & $13(56.5)$ & $10(43.5)$ \\
\hline \multirow{2}{*}{ 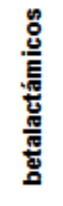 } & Ampicilina & $1(4.3)$ & $22(95.7)$ \\
\hline & Peniciina & $0(0)$ & $23(100)$ \\
\hline \multirow{2}{*}{ 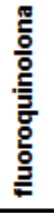 } & Norfloxacina & $2(8.7)$ & $21(91.3)$ \\
\hline & Enrofloxacina & $2(8.7)$ & $21(91.3)$ \\
\hline \multirow{2}{*}{ 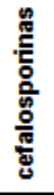 } & Cefiotur & $17(73.9)$ & $6(26.1)$ \\
\hline & Cefalexina & $3(13)$ & $20(87)$ \\
\hline \multirow{2}{*}{ 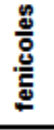 } & Flortenicol & $15(65.2)$ & $8(34.8)$ \\
\hline & Tianfenicol & $13(56.5)$ & $10(43.5)$ \\
\hline \multirow{2}{*}{ 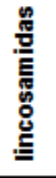 } & Lincoespecin & $11(47.8)$ & $12(52.2)$ \\
\hline & Lincomicina & $1(4.3)$ & $22(95.7)$ \\
\hline 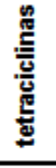 & Oxtetracicina & $2(8.7)$ & $21(91.3)$ \\
\hline 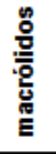 & Tilosina & $1(4.3)$ & $22(95.7)$ \\
\hline 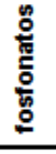 & Fosfomicina & $5(21.7)$ & $18(78.3)$ \\
\hline 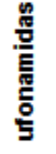 & Sulfametoxazol & $3(13)$ & $20(87)$ \\
\hline
\end{tabular}

identificaron bioquímicamente. Esto se confirmó genotípicamente por la amplificación, mediante la PCR de los segmentos específicos que codifican para los genes $16 \mathrm{~S}$ rRNA y $23 \mathrm{~S}$ rRNA, estipulados en diversos métodos ${ }^{(19,23,29)}$. Se debió haber tenido un marcador molecular más específico para determinar los pares de bases con mayor exactitud y descartar del 1030 a 1080 propuesto por Bojesen et $a^{(23)}$. La PCR puede ser útil para el diagnóstico de rutina de Gallibacterium. Si bien, el uso de los métodos moleculares es limitado debido a los altos costos de la PCR (3 veces más caro que una bacteriología), también ahorra tiempo sin tener que recurrir a las pruebas fenotípicas, las cuales suelen llevar días antes de obtener un resultado.

La patogenia de $G$. anatis está poco definida, por lo que existen pocos estudios que expliquen la farmacocinética de este microorganismo, lo que ha inclinado al productor a medicar desmedidamente esta enfermedad, ocasionando que la bacteria desarrolle una resistencia marcada, como se ha demostrado(30,31), al comparar los fenotipos de resistencia con los informes de otros taxones de Pasteurellaceae, encontrándose una alta multirresistencia de las tetraciclinas y sulfametoxazol del 92 y $97 \%$ en los aislamientos de campo de

Figura 4. Porcentajes de resistencia de los aislamientos de Gallibacterium anatis

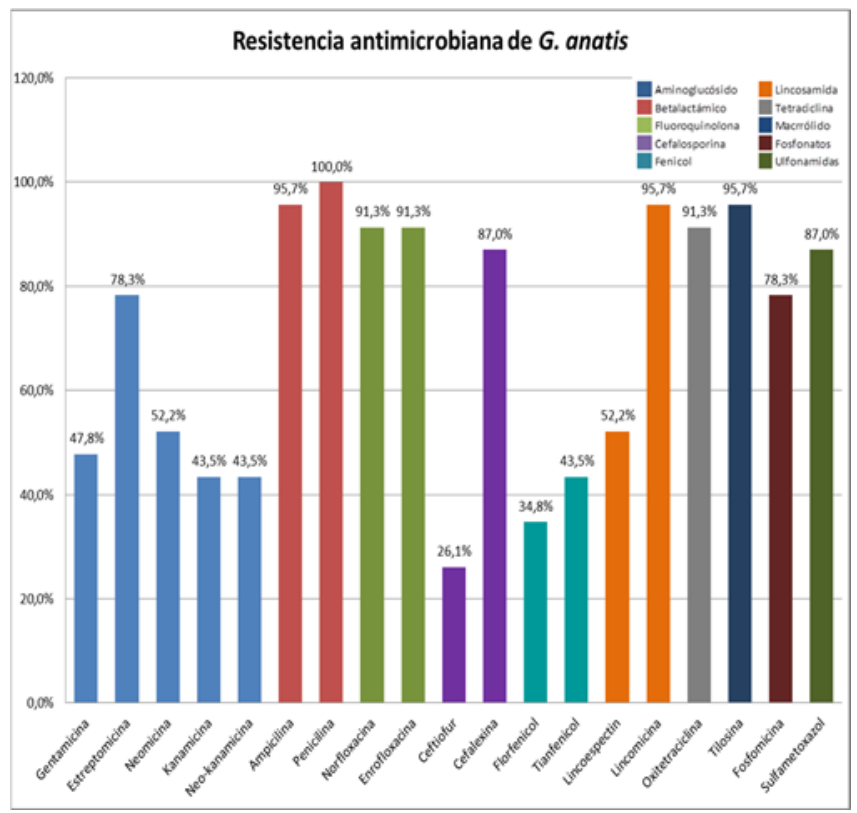


Gallibacterium. Confirmando así los resultados obtenidos en el presente estudio, donde la mayoría de los aislamientos presentaron resistencia marcada con las tetraciclinas y los betalactámicos.

En este estudio, los aislamientos resultaron altamente resistentes, indicando la dificultad para el control de esta infección; la medicación no se debería de aplicar sin algún análisis de susceptibilidad antimicrobiano previo, para poder prescribir correctamente los antibióticos, considerando también la naturaleza del proceso infeccioso, la historia clínica, la vía de administración, la dosis, la duración del tratamiento, el mecanismo de acción del antibiótico y su toxicidad(27). Sin embargo, aunque la resistencia parezca ser muy común entre los aislamientos de $G$. anatis, los que no son de campo, muestran menor resistencia a algunos antibióticos ${ }^{(30)}$.

Se puede concluir que los resultados de este trabajo muestran que la presencia de Gallibacterium anatis está frecuentemente asociada a problemas respiratorios y reproductivos en las poblaciones de gallinas de postura comercial en el sur de Sonora, afectando la producción. Los aislamientos de $G$. anatis mostraron una resistencia marcada a distintos antibióticos, probablemente por la medicación desmedida ante la presencia de microorganismos, lo que sugiere implementar un programa eficiente de control para esta bacteria.

\section{AGRADECIMIENTOS}

Este trabajo fue parcialmente apoyado por Pecuarius Laboratorios SA de CV. Se agradece al Dr. Miki Bojesen, por su disposición y apoyo al proporcionar información sobre el tema.

\section{LITERATURA CITADA}

1. Mirle $C$, Schoengarth $M$, Meinhart $H$, Olm U. Studies into the incidence of Pasteurella haemolytica infections and their relevance to hens, with particular reference to diseases of the egg-laying apparatus. Monat Vet 1991;(45):545-549.

2. Bager RJ, Persson G, Nesta B, Soriani M, Serino L, Jeppsson M. Outer membrane vesicles reflect environmental cues in Gallibacterium anatis. Vet Microbiol 2013;167(3-4):565-572.
3. Bojesen AM, Nielsen SS, Bisgaard M. Prevalence and transmission of haemolytic Gallibacterium species in chicken production systems with different biosecurity levels. Avian Pathol 2003;32(5):503-510.

4. Mirle $C$, Schöngarth $M$, Meinhart $H$, Olm U. Studies into the incidence of Pasteurella haemolytica infections and their relevant to hens, with particular reference to diseases of the egg-laying apparatus. Monatshefte für Veterinärmedizin 1991;(45):545-549.

5. Mushin R, Weisman Y, Singer N. Pasteurella haemolytica found in respiratory tract of fowl. Avian Dis 1980;24(1):162-168.

6. Rzewuska M, Karpiñska $E$, Szeleszczuk $P$, Binek M. Isolation of Gallibacterium spp. from peacocks with respiratory tract infections. Med Weter 2007;63(11):1431-1433.

7. Kristensen BM, Frees D, Bojesen AM. GtxA from Gallibacterium anatis, a cytolytic RTX-toxin with a novel domain organization. Vet Res 2010;(41):25-29.

8. García-Gómez E, Vaca S, Pérez-Méndez A, Ibarra-Caballero J, Pérez Márquez V, Tenorio VR. Gallibacterium anatis secreted metalloproteases degrade chicken IgG. Avian Pathol 2005;(34):426-429.

9. Bager RJ1, Nesta B, Pors SE, Soriani M, Serino L, Boyce JD, Adler B, Bojesen AM. The fimbrial protein FlfA from Gallibacterium anatis is a virulence factor and vaccine candidate. Infect Immun 2013; 81(6):1964-1973.

10. Bisgaard M. Incidence of Pasteurella haemolytica in the respiratory tract of apparently healthy chickens and chickens with infectious bronchitis. Characterization of 213 strains. Avian Pathol 2007;6(4):285-292.

11. Alispahic M, Christensen $H$, Hess C, Razzazi-Fazeli E, Bisgaard M, Hess M. MALDI-TOF mass spectrometry confirms clonal lineages of Gallibacterium anatis between chicken flocks. Vet Microbiol 2012;(160):269-273.

12. Paudel S, Alispahic M, Liebhart D, Hess M, Hess C. Assessing pathogenicity of Gallibacterium anatis in a natural infection model: the respiratory and reproductive tracts of chickens are targets for bacterial colonization. Avian Pathol 2013;(42):6-12.

13. Aarestrup FM, Seyfarth AM, Angen O. Antimicrobial susceptibility of Haemophilus parasuis and Histophilus somni from pigs and cattle in Denmark. Vet Microbiol 2004;101(2):143-146.

14. Aarestrup FM. Veterinary drug usage and antimicrobial resistance in bacteria of animal origin. Basic Clin Pharmacol Toxicol 2005;(96):279-285.

15. Bojesen AM, Vázquez ME, Bager RJ, Ifrah D, González C, Aarestrup FM. Antimicrobial susceptibility and tetracycline resistance determinant genotyping of Gallibacterium anatis. Vet Microbiol 2011;148(1):105-110.

16. Unión de Asociaciones Avícolas del Estado de Sonora (UAAES). 1999.

17. Lowenstine LJ. Necropsy procedures. In: Harrison GJ, Harrison LR editors. Clinical avian medicine and surgery. USA: WB Saunders Co; 1986;23:298-309.

18. Woodford MH, Keet DF, Bengis RG. Postmortem procedures for wildlife veterinarians and field biologists. Published jointly by the Office International des Epizooties, Care for the Wild and the Veterinary Specialist Group/Species Survival Commission of the World Conservation Union (IUCN) 2000;54-55. 
19. Christensen H, Bisgaard M, Bojesen AM, Mutters R, Olsen JE. Genetic relationships among avian isolates classified as Pasteurella haemolytica, "Actinobacillus salpingitidis" or Pasteurella anatis with proposal of Gallibacterium anatis gen. nov., comb. nov. and description of additional genomospecies within Gallibacterium gen. nov. Int J Syst Evol Microbiol 2003;(53):275-287.

20. Rimler RB, Sandhu TS, Glisson JR. Pasteurellosis, infectious serositis, and pseudotuberculosis. In: A laboratory manual for the Isolation and Identification of avian pathogens. Swayne DE editor. Philadelphia: American Association of Avian Pathogens; 1998.

21. DGRM-01. Guía rápida de operación con sistema LABPRO. DICIPA. 2006.

22. Bisgaard M. Isolation and characterization of some previously unreported taxa from poultry with phenotypical characters related to Actinobacillus and Pasteurella species. Acta Patholo Microbiol Immunol 1982;(90):59-67.

23. Bojesen AM, Vázquez ME, Robles F, González C, Soriano EV, Olsen $\mathrm{JE}$, Christensen H. Specific identification of Gallibacterium by a PCR using primers targeting the $16 \mathrm{~S}$ rRNA and $23 \mathrm{~S}$ rRNA genes. Vet Microbiol 2007;123(1-3):262-268.

24. Lane DJ. 16S/23S rRNA sequencing. In: Stackebrandt E, Goodfellow MN editors. Nucleic acid techniques in bacterial systematics. Chichester United Kingdom: John Wiley and Sons; 1991.
25. National Committee for Clinical Laboratory Standards (NCCLS). Performance standards for antimicrobial susceptibility testing: 12th Inform Suppl. Wayne (PA): NCCLS, Document M100-S12; 2002;22(1):15-39.

26. Barry AL, Thornsberry C. Susceptibility test diffusion test procedures. In: Lennette E editor. Manual of clinical microbiology, $4^{\text {th }}$ ed. Am Soc Microbiol $1985 ; 978-987$.

27. Quinn PJ, Markey BK, Manguirre D. Elementos de la microbiología veterinaria. México: Acribia; 2003.

28. Bojesen AM, Torpgahl M, Christensen H, Olsen JE, Bisgaard M. Genetic diversity of Gallibacterium anatis Insolates from different chicken flocks. J Clin Microbiol 2003;41(6):2737-2740.

29. Tegtmeier $C$, Angen $O$, Ahrens P. Comparison of bacterial cultivation, PCR, in situ hybridization and immunohistochemistry as tools for diagnosis of Haemophilus somnus pneumonia in cattle. Vet Microbiol 2000;76(4):385-394.

30. Bojesen AM, Vázquez ME, Bager RJ, Ifrah D, González C, Aarestrup FM. Antimicrobial susceptibility and tetracycline resistance determinant genotyping of Gallibacterium anatis. Vet Microbiol 2011;148:105-110.

31. Bojesen AM, Bager RJ, Ifrah D, Aarestrup FM. The rarely reported tet (31) tetracycline resistance determinant is common in Gallibacterium anatis. Vet Microbiol 2011;149:497-499. 